\title{
PRODUCTION NOTES
}

Corresponding author

Name: Catherine Steel

Email: csteel@unimelb.edu.au

Article Type: OA

Journal Section: Equine

Layout Instructions

Figures: 3

Tables: 1

Word Count (approx.) 7067

Prevalence, radiographic resolution and outcomes of slab fractures of the third and central tarsal bones in juvenile Thoroughbred horses

CM Steel, ${ }^{a^{*}}$ VL Collins, ${ }^{a}$ SR Hance, ${ }^{b}$ AR Adkins ${ }^{c}$ and PL Hitchens ${ }^{a}$

${ }^{*}$ Corresponding author.

${ }^{a}$ Equine Centre, Faculty of Veterinary and Agricultural Sciences, University of Melbourne, 250 Princes Hwy, Werribee, Victoria 3030, Australia; csteel@unimelb.edu.au

bStephen Hance LLC, Oklahoma City, Oklahoma 73122, USA

'Scone Equine Hospital, Scone, New South Wales, Australia

Background Veterinarians are required to interpret the significance of radiographic findings for sale, soundness and future racing performance of weanling and yearling Thoroughbreds. We investigated the prevalence and radiographic appearance of slab fractures of the third (T3) and central tarsal (Tc) bones.

Methods All radiographs in a database that had been evaluated by a Diplomate of the American College of Veterinary Surgeons with extensive experience in interpreting pre-sale radiographs of juvenile Thoroughbreds were evaluated for the prevalence, radiographic appearance at initial diagnosis and after continued pasture turnout, as well as prognosis for racing, of fractures of T3 and Tc.

Results Fractures were identified in 186 tarsi (184 T3 fracture only, 1 Tc fracture only, 1 Tc and T3 fracture) of 157 horses (126 unilateral T3, 29 bilateral T3, 1 contralateral Tc and T3, 1 unilateral Tc and T3) from 7676 examinations. The prevalence of T3 and Tc fracture was $2.40(95 \% \mathrm{Cl} 2.07,2.76)$ and $0.04(95 \% \mathrm{Cl} 0.01,0.11)$ per 100 radiographic examinations respectively. Fractures were identified on D556-65 MPILO view and occurred by survey examination at $11.1 \pm 1.3$ months in $85.7 \%$ horses. At initial diagnosis, $84.3 \%$ T3 fractures appeared incomplete and involved the distal articular surface. Fracture score improved $(P<0.001)$, dorsal modelling $(P<0.001)$ and osteoarthritis score increased in the distal intertarsal joint $(P<0.001)$ but not the tarsometatarsal joint between survey and repository examination. Fractures healed by repository examination in $71.9 \%$ tarsi if there was $>6$ months between examinations. There was no difference in sale price, and horses with T3 fractures had fewer trials when 2 and 3 years old $(P=0.023)$, yet no difference in other parameters of racing success when 2 or 3 years old compared with controls.

Conclusion Tarsal slab fractures can occur in juvenile Thoroughbreds and most heal with continued pasture turnout of $>6$ months. Further investigation is required to

This is the author manuscript accepted for publication and has undergone full peer review but has not been through the copyediting, typesetting, pagination and proofreading process, which may lead to differences between this version and the Version of Record. Please cite this article as doi: $10.1111 /$ avj.12790

This article is protected by copyright. All rights reserved. 
determine risk factors and before making firm conclusions regarding the optimal management, prognosis for racing and long-term soundness.

Keywords repository radiographs; slab fractures; survey radiographs; tarsus; Thoroughbred yearlings

Abbreviations AUD, Australian dollars; $\mathrm{Cl}$, confidence interval; DITJ, distal intertarsal joint/centrodistal joint; DPI, dorsoplantar; DMPILO, dorsomedial-plantarolateral oblique; LM, lateromedial; OA, osteoarthritis; OR, odds ratio; PITJ, proximal intertarsal joint/talocalcanealcentroquatral joint; T3, third tarsal bone; Tc, central tarsal bone; TMTJ, tarsometatarsal joint

Weanling survey radiographs are obtained by vendors to identify horses that may need treatment of musculoskeletal disease before sale. Later, a defined set of repository radiographs are obtained within 42 days of public auction. Few new radiographic lesions form between weanling and yearling examinations, ${ }^{1}$ many lesions improve and some resolve. ${ }^{1-3}$ Veterinarians are required to interpret the significance of radiographic findings for sale, soundness and future racing performance. ${ }^{4,5}$ Studies have assessed the prevalence of some of these radiographic changes, ${ }^{1,6-13}$ and their association with subsequent performance ${ }^{8,12,14-16}$ although limitations associated with these studies, including the low power of those that have evaluated less common lesions, have been recognised. ${ }^{4}$

We have recognised incomplete and complete slab fractures of the third (T3) and central tarsal bones $(\mathrm{Tc})$ on survey and repository radiographs, yet the prevalence and significance of such findings have received little attention ${ }^{12}$ and whether these lesions improve or resolve between survey and repository examinations has not been assessed. Instead, reports concerning T3 and Tc fractures describe stress fractures and partial or complete slab fractures that occur occasionally in horses in race training, presumably when the bone has not adapted to the loading environment. ${ }^{17-22}$ In some cases these injuries may be associated with a 'wedge' shape of this bone in which the articular surfaces of T3 converge then diverge again on the dorsolateral aspect. ${ }^{23}$

The outcome following conservative management of T3 and Tc fractures in adult horses has been reported, with approximately $70 \%$ of horses returning to racing. ${ }^{17,19,20,22}$ Surgical management of T3 fractures, particularly using a minimally invasive lag screw technique, may improve this prognosis, ${ }^{22}$ yet a larger study is needed to make a firm conclusion. The outcome for juvenile horses with T3 and Tc fractures diagnosed before entering race training has not been adequately reported. The only study of yearling radiographs to report tarsal bone slab fractures lacked sufficient power to make a firm conclusion regarding prognosis. ${ }^{12}$

The purposes of this study were to determine (1) the prevalence and radiographic appearance of T3 and Tc fracture in juvenile Thoroughbred horses before entering race training, (2) whether radiographic evidence of T3 or Tc fracture affects purchase price, (3) whether radiographic healing occurs despite continued pasture turnout and (4) whether horses in which healing is complete race successfully as 2- and 3-year-olds. We hypothesised that fractures of T3 and Tc are uncommon in juvenile Thoroughbreds, can reduce purchase price, may be associated with 'wedge' tarsal bone conformation and osteoarthritis $(\mathrm{OA})$ and usually heal with conservative management to allow similar racing success to peers.

\section{Study population}

\section{Materials and methods}

The Scone Equine Hospital imaging database of Thoroughbred survey, weanling sale and yearling sale radiographs was searched using the terms 'slab fracture' and 'tarsus' from 1 June 2010 to 1 April 2016. All radiographs in the database had been evaluated by a 
Diplomate of the American College of Veterinary Surgeons with extensive experience in interpreting pre-sale radiographs of yearling Thoroughbreds $(\mathrm{SRH})$ and findings were reported in the records. The tarsal radiograph series included a dorso-55-65 medialplantarolateral oblique (D55-65 MPILO), a dorso-10-20 lateral-plantaromedial oblique (DPI) and a lateromedial (LM) view as part of the routine 34-42 radiograph series used for pre-sale evaluation. ${ }^{10}$ An 'examination' was defined as a radiograph series of both tarsi obtained on the same date. Date of birth, dam, sire, sex and date of examination were recorded. All horses were managed conservatively with unrestricted paddock turnout after diagnosis.

\section{Evaluation of radiographic bone changes}

Horses were included if a unilateral or bilateral incomplete or complete slab fracture of Tc or T3 was reported in the database and there was agreement with the diagnosis following evaluation of the radiographs by a second observer (VLC). If the second observer did not agree, a third observer (CMS) evaluated the tarsal radiographs and the case was excluded if evidence of fracture was considered inconclusive. Limb(s) affected and fracture location (T3 or Tc) were recorded. The extent of the fracture was determined as a percentage of T3 or Tc bone height on the D55-65 MPILO view. The distance from the fracture to the dorsal articular margin of the affected tarsal bone and the width of the linear lucency ('fracture gap') $(\leq 1 \mathrm{~mm}$ or $>1 \mathrm{~mm}$ ) were recorded. Radiographs were viewed as DICOM files and the digital imaging software OsiriX (v.8.0. OsiriX Imaging Software, Geneva, Switzerland) was used to make all measurements.

Fracture healing was graded from 1 to 6 on the D55-65'MPILO view (Figure 2) as stage 1 if there was a radiolucent line with sharp clear edges, stage 2 if there was slight blurring of the fracture line, stage 3 if there was marked blurring of the fracture line, stage 4 if the fracture line was partly (<_50\% of its length) ossified or appeared incomplete, stage 5 if the fracture line was ossified in most areas (> $50 \%$ of its length) but still had a short remaining fracture line evident, and as stage 6 if healing was complete with no radiographic evidence of the previously diagnosed fracture.

Dorsal modelling of T3 and Tc was described using the D55-65 MPILO and LM views and scored as nil (0), mild (1), moderate (2) or severe (3) bone proliferation (Figure 1). Wedging (the degree of convergence and divergence of the articular surfaces) of T3 and Tc were graded and scored for analysis as nil (0), mild (1), moderate (2) or severe (3) on the LM and D55-65 MPILO view as previously described. ${ }^{23}$

\section{Evaluation of $O A$}

The centrodistal (distal intertarsal joint (DITJ)) and tarsometatarsal joint (TMTJ) were evaluated using all three radiographic views for joint space narrowing, subchondral bone sclerosis (thickening of the zone of subchondral opacity), subchondral bone lysis and periarticular modelling. Each variable was graded on a scale of $0-3(0=$ none, $1=$ mild, $2=$ moderate, $3=$ severe) and the scores were summed for each joint to give an overall grade of radiographic severity of OA: $1=$ mild $(0-4) ; 2=$ moderate $(5-8) ; 3=$ marked $(9-12) .{ }^{24}$

\section{Sale price and racing performance}

Yearlings with tarsal fracture (cases) were one-to-one matched with a maternal sibling control. If more than one control was identified for a case, then the sibling closest in age was used and cases and controls were further matched by sex if possible. Race performance for each case-control pair was compared for their 2-year-old (from 1 October in 
the year they turned 2 to the following 31 July) and 3-year-old (1 August to following 31 July) racing seasons.

The sale price was obtained from an online Thoroughbred auction database. ${ }^{25}$ Race performance information was obtained from the official repository of Australian racing results. ${ }^{26}$ For each animal the number of barrier trials, number of race starts, number of times placed, number of wins, total prize money (AUD) and yearling sale price (AUD) were recorded.

\section{Statistical analysis}

The distributions of continuous (e.g. age in months) and ordinal variables (graded scales) were assessed using the Shapiro-Wilk test and by examining histograms. Mean and standard deviation $( \pm S D)$ are presented for continuous sales price and performance variables. Because most grade scores were non-normally distributed, median and interquartile ranges are presented. Correlations between grades indicating bone changes and OA were assessed using pairwise Spearman's rank correlation coefficient (rho) (Supplementary Table 1).

As an indicator of fracture healing we assessed differences between the survey and repository radiographic results for horses with two radiographic series available. For differences between scores we used the Wilcoxon signed rank sum test and for differences between normally distributed continuous measures we used a paired t-test. Other variables included in analysis were the location (T3, Tc, distance from dorsal aspect), extent of the fracture (\% of height) and the fracture gap width. We fitted univariable conditional logistic regression models to test trends in changes to the proportion of observed tarsal fractures over the study period and to assess whether there were any differences in sales price and performance variables (number of starts, wins, places, earnings) in the 2-year-old and 3year-old race seasons for horses with fracture(s) compared with maternally matched controls. Odds ratios (OR) with 95\% confidence intervals $(\mathrm{Cl})$ are presented. Statistical significance was set at $P \leq 0.05$. Statistical analyses were conducted using Stata/SE, version 14.2 (StataCorp, College Station, TX, USA).

\section{Results}

The database search included 7676 radiographic examinations (3844 survey, 508 weanling pre-sale and 3324 yearling pre-sale) and identified 180 horses reported as having an incomplete or complete slab fracture of T3 or Tc in one or both tarsi. Of these, 23 horses were excluded from the study because of lack of agreement regarding diagnosis between observers, resulting in 186 tarsi (unilateral fracture in 128 horses and bilateral fracture in 29 horses) of 157 horses (70 colts, 87 fillies) with a fracture initially diagnosed on survey (119 tarsi, 116 with T3 fracture and 3 with Tc fracture, of 100 horses) or repository (66 tarsi, all with T3 fracture, of 57 horses) radiographs; 4 of these horses had a fracture diagnosed on survey radiographs of one tarsi and a second fracture of the contralateral limb diagnosed on repository radiographs, and 17 had bilateral fractures on survey radiographs. A T3 fracture was evident at 184 examinations and a Tc fracture was evident at 3 examinations. The proportion of radiographs with T3 fracture increased over the study period (Table 1; $P=0.003$ ). Horses were $11.1 \pm 1.3$ months of age at survey radiographic examination and $16.2 \pm 1.9$ months when yearling repository radiographs were obtained. For horses that had both survey and repository radiographs, the mean time between examinations was 5.5 months ( \pm 2.0 ; range 1.4-15.7); 26 horses had only survey radiographs available, 38 horses had only repository radiographs and 93 horses had both survey and repository radiographs. Of this latter group, both of the radiographic examinations were evaluated for 111 affected tarsi and a fracture was initially diagnosed on survey examination in 89 tarsi of 76 horses. 
The prevalence of T3 fracture (score 1-5) was 2.40 (95\% Cl 2.07, 2.76; 184/7676) and for Tc fractures was $0.04(95 \% \mathrm{Cl} 0.01,0.11 ; 3 / 7676)$ per 100 radiographic examinations. Of the 119 horses with survey radiographs, T3 or Tc fracture was evident on this examination in 102 horses $(85.7 \%)$.

Fractures occurred in the dorsolateral aspect of T3 in a dorsomedial to plantarolateral orientation and were most readily seen on the D55-65 MPILO view within $0.65 \mathrm{~cm}$ of the dorsolateral articular margin and in the sagittal plane. At initial diagnosis, two T3 fractures $(2 / 185,1.08 \%)$ were clearly complete and none were significantly displaced. The remaining fractures appeared incomplete and involved the distal articular surface (156/185, 84.32\%), the proximal articular surface $(8 / 185,4.32 \%)$ or neither $(21 / 185,11.35 \%)$. When including initial and follow-up radiographs (208 tarsi), a linear lucency $<1 \mathrm{~mm}(120 / 208,57.69 \%)$ or $>1 \mathrm{~mm}(88 / 208,42.31 \%)$ in width was present, wedging of T3 was absent $(146 / 208$, $70.19 \%)$, mild (40/208 tarsi $19.23 \%)$, moderate $(17 / 208$ tarsi, $8.17 \%)$ or severe $(5 / 208$ tarsi, $2.40 \%)$.

Radiographic changes between survey and repository radiographs for horses that had both examinations are described in Supplementary Table 2 (categorical and ordinal variables) and Supplementary Table 3 (continuous variables). There was significant improvement in fracture score indicating progression toward healing $(P<0.001)$, increase in modelling $(P<0.001)$ and increase in OA score in the DITJ but not the TMTJ $(P<0.001)$ between the survey and repository examinations (Supplementary Table 2). The distance from the proximal extent of the fracture to the proximal articular surface of the fractured tarsal bone significantly increased between the survey and repository examinations as fracture height significantly decreased with progression toward healing (Supplementary Table 3). Of the 89 tarsi of 76 horses with fracture initially diagnosed on survey radiographs and for which repository radiographs were also available, the fracture had completely healed radiographically (score 6 ) in 64 tarsi of 57 horses. Radiographic evidence of healing (stage 6 ) had occurred by repository radiographic examination in two tarsi $(2 / 89,2.2 \%$ tarsi) within 3 months, in 29 tarsi $(29 / 89,32.6 \%$ tarsi) that had at least 3 months but no more than 6 months between examinations and in 33 tarsi $(33 / 89,37.1 \%$ of tarsi) if there was $\geq 6$ months between survey and repository radiographic examinations. Therefore, $34.8 \%(31 / 89)$ of tarsal fractures healed within 6 months and $71.9 \%$ (64/89) of fractures by the time repository radiographs were obtained if at least 6 months had elapsed. The duration of fracture when diagnosed on survey radiographs was unknown, yet mean time to healing after this examination was 5.64 months ( $n=64$, SD 1.88, range 2.37-9.33 months). All but one tarsus, even those with $<3$ months between examinations, had evidence of progression toward healing (a higher average fracture healing score/stage) with mean improvement in score of 2.78 (SD 1.01, range 1-5).

Of the three tarsi with Tc fracture, one filly had bilateral Tc fractures (complete slab fracture of the right tarsus and an incomplete fracture of the left tarsus), yet only a survey radiographic series was available. This filly never raced. The second filly (Figure 3 ) had an incomplete Tc fracture of the left tarsus on survey radiographs, with progression of fracture healing (from stage 3 of survey radiographs to stage 5 on repository radiographs). A Tc fracture of the right tarsus was suspected on survey radiographs, but was not reported because of the lack of agreement among reviewers. This filly also had an incomplete, stage 3 T3 fracture of the right tarsus on survey radiographs that had radiographic evidence of partial healing (stage 5) on repository radiographs and an incomplete fracture of the dorsoproximal aspect of the left third metatarsal bone involving the TMTJ. The filly had four trials but was unplaced in each and was retired without racing. 
Horses that had been diagnosed with T3 or Tc fracture competed in fewer trials as a 2 or 3 year olds (mean 1.72, SD 1.79) compared with controls (mean 2.24, SD 2.20) $(P=0.023)$ (Supplementary Table 4). There was no difference between controls and cases when comparing sale price, whether horses had started in a race as a 2- or 3-year-old, number of starts, placings, wins and earnings as a 2- and 3-year-old (Supplementary Table $4)$.

There was no difference in sale prices for Thoroughbred horses with both survey and repository radiographs that had any evidence of fracture (fracture score 1-5) on repository radiographs $(n=73 ; \$ 108,226$ SD $\$ 127,755)$ compared with their matched controls $(n=71$; $\$ 106,669$ SD $\$ 119,198 ; P=0.937$ ), or obvious evidence of fracture (fracture score 1-2) on repository radiographs $(n=15 ; \$ 101,400$ SD 146,004) compared with their matched controls $(\mathrm{n}=17 ; \$ 102,853$ SD $\$ 97,777 ; \mathrm{P}=0.787)$.

\section{Discussion}

Horses with T3 fracture subsequently had fewer trials when 2- and 3-year-olds compared with their peers, yet it is unclear whether this is causal and potentially related to a delay in the onset of race training or lameness caused by the tarsal injury or merely an association in these cases. There was no difference for other performance variables including number of starts and total prize money. The lack of reduction in racing success associated with T3 fractures in juvenile horses should be confirmed in a larger study before a firm conclusion is made. Only two horses had Tc fractures and neither of them raced. This is an insufficient number of Tc fractures to make a conclusion regarding prognosis and the effect of Tc fractures in juvenile horses on future racing potential remains to be determined.

Contrary to our hypothesis there was no difference in the mean sale price of horses with tarsal fracture compared with controls, even if the fracture was still evident on repository radiographs. This may be because some veterinarians interpreting repository radiographs did not identify fractures, buyers or veterinarians making recommendations on purchase did not consider these fractures likely to affect future racing potential, believed that any distal tarsal joint lameness could be managed with medication or because other factors that may have affected the sale price of cases or factors affecting the sale price of controls were unknown.

T3 slab fracture was uncommon, which was an expected outcome. We report a prevalence of 2.40 examinations with a T3 fracture per 100 radiographic examinations in juvenile Thoroughbred horses and a much lower prevalence for Tc fractures. We were unable to report a prevalence in horses as we did not determine the number of horses included in the 7676 radiographic examinations in the database and the database is likely to have included horses that were radiographed on one, two and possibly three occasions. Tarsal slab fracture was detected in $1.4 \%(14 / 976)$ of horses in a study of repository radiographs of Japanese yearlings. ${ }^{12}$ However, as many of the T3 fractures in weanlings had healed by yearling repository examination, including only the yearling repository radiographs is likely to underestimate the prevalence of T3 fracture in juvenile Thoroughbreds. Only the views provided in the standard survey and repository radiographs were available in the current study, which may have decreased the number of fractures identified. The incidence of fractures may have been higher if additional DMPILO views using different angles were obtained. However, not all tarsal fractures are evident radiographically even if multiple views are obtained. ${ }^{27}$ Missed or incorrect diagnoses and disagreement between observers are more prevalent for subtle lesions on pre-sale radiographs. ${ }^{1,10,28}$ We limited observer error by using a systematic approach and defined scoring criteria, but did exclude 23 of the 180 radiographic examinations for which $\mathrm{T} 3$ or Tc fracture was diagnosed when initially reported 
by a highly experienced observer as the other observers did not both agree with the diagnosis. Again, the true prevalence of these tarsal fractures may have been higher than we report. Benefits of computed tomography ${ }^{29}$ and $\mathrm{MRI}^{27}$ for improving diagnostic accuracy have been recognised when imaging this region, but would not be practical for pre-sale screening of a large number of horses and would be difficult to justify in horses that are not examined because of lameness. Furthermore, radiographs may underestimate the number of fractures that are in fact compete, compared with computed tomography. ${ }^{27}$

Wedge-shaped conformation of T3 and Tc with the articular surfaces converging then diverging again has been proposed as increasing the risk of tarsal slab fracture, ${ }^{23}$ yet this was based on comparison of the shape of these bones in a small number of adult horses with and without tarsal slab fracture and was only identified in 3 of 17 horses in another case series. ${ }^{22}$ Although in some cases in the current study T3 fracture and T3 'wedging' was present, $70 \%$ of fractured bones did not have a wedge conformation. We did not evaluate the prevalence of wedging in control horses so we could not evaluate whether this is associated with a risk of fracture. We did not conduct a repeatability study to evaluate wedging or the OA score. An additional limitation of retrospective evaluation of radiographs is that we were unable to account for any magnification error in measurements as a radioopaque marker of known dimensions was not placed adjacent to the tarsus. Although this may introduce a small error when reporting the distance of the fracture to the dorsal articular margin of the affected tarsal bone, it would not affect grading of wedging because this was based on a ratio of the minimum to maximum width between the articular surfaces of the bone. ${ }^{23}$

Most fractures were present on survey radiographs and, as hypothesised, appeared completely healed on repository radiographs. There was radiographic progression toward healing in all others, apart from one tarsi despite continued pasture turnout. Although standardised radiographic projections were obtained, we cannot rule out the possibility of slight variation between survey and repository radiographs in the D55-65 MPILO angle, which may have influenced how fracture healing was assessed. As the duration of fractures at the time of survey radiographs being obtained was unknown, it is difficult to be certain of the time required for fracture healing; however, it appears that to ensure fracture healing in most horses, a minimum of 6 months is needed following diagnosis. Whether surgical repair and/or a period of stricter confinement would reduce the time required for healing remains to be determined.

A factor that may be important in determining whether tarsal slab fracture adversely affects future performance may be whether OA of the distal tarsal joints occurs. Radiographic lesions of OA are most commonly seen on the dorsomedial or dorsolateral aspects of the TMTJ and DITJ. ${ }^{9,30}$ Dorsomedial lesions would be superimposed on the D55$65^{\circ} \mathrm{MPILO}$ view used in this study and therefore radiographic signs of OA could have been underdiagnosed because only standard repository views were obtained. Osteophytes and enthesiophytes of the distal tarsal joints (particularly the DITJ) are the only tarsal condition evaluated previously that may be associated with a reduction in 2- and 3-year olds' racing success. ${ }^{14}$ In the current study, although the fracture usually involved the distal articular surface, there was an increase in the OA score in the DITJ, but not the TMTJ, between survey and radiographic examinations, suggesting that loading conditions that caused fracture may also result in some degree of OA that may or may not be of clinical significance, particularly because fracture was not associated with reduced racing success. A limitation of the current study is that the outcome was racing ability and whether any 
horses developed lameness because of OA of the distal tarsal joints that was treated and if this affected the outcome is unknown.

There was only a very weak correlation between Tc wedging and DITJ OA and TMTJ

OA (Table 1). Sprackman et al. reported an association between dorsal wedging of T3 and mild-moderate OA and between plantar wedging and severe OA. ${ }^{29}$ We did not detail the type of wedging seen in the juvenile horses in the current study because we found interpretation of radiographs as previously described difficult with the superimposition of the tarsal bones. ${ }^{23,31}$

In other studies, T3 fractures have been diagnosed most commonly in Thoroughbreds during their first year of race training, in a repeatable location with a dorsomedial to plantarolateral orientation through the dorsolateral aspect of the dorsal facet of T3, not associated with a specific traumatic event, and have therefore been considered to be stress fractures. ${ }^{22}$ Given our findings, the possibility of pre-existing incomplete T3 fracture in horses diagnosed during their first year of training warrants further investigation. In the current study, most tarsal fractures were diagnosed on weanling survey radiographs. None of them were reported to be lame at the time of radiographic examination and there was no reported history or signs of external trauma. Fractures had a similar predictable configuration to those in adult horses, ${ }^{22}$ occurred in the dorsolateral aspect of T3 and were invariably incomplete, and thus may also be considered as stress fractures. Subchondral bone modelling in T3 and Tc, evident by around 2 years of age, also mainly affected the dorsolateral aspect of the tarsus. ${ }^{32}$ Pasture exercise alone appears to provide sufficient biomechanical loading to increase bone density within T3 in foals. A similar increase in T3 bone density was present at 5 months of age in foals that had exercised only spontaneously at pasture and in boxed foals that had an imposed sprint training program compared with unexercised foals. ${ }^{33}$ We propose that the cause of tarsal fractures in juvenile horses is repeated high loading of the dorsolateral aspect of the tarsus during pasture turnout and that increased body mass or malalignment are possible contributing factors. A fracture, extending from the TMTJ into the third metatarsal bone, within $0.65 \mathrm{~cm}$ of the dorsal articular margin, was observed in three horses in the current study (Figure 3). We have also recognised fragmentation adjacent to the dorsal aspect of the distal talus, distal to the lateral trochlear ridge in juvenile Thoroughbred horses (Devery et al., unpubl. data) (Figure 3a). We presume these conditions are also likely to be caused by increased cyclic loading of the dorsal aspect of the tarsus. A limitation of the current retrospective study is that body weight or condition score and limb conformation were not recorded and any history of incomplete ossification of the tarsal bones following birth was unknown; however, these factors may influence whether excessive loads are placed on the tarsal bones. Greater body condition score was associated with greater severity of radiographic signs of distal tarsal osteoarthritis in juvenile Brazilian Crioulo horses. ${ }^{34}$ Outward rotation of the hindlimbs, which improves as musculature develops during growth, is common in yearlings, ${ }^{35}$ yet the effect of this on the risk of injury is also unknown.

There was an increase in the proportion of horses with tarsal fractures per year over the study period. Although it is possible that veterinarians evaluated radiographs more closely in later years for evidence of these fractures, further investigation is required to determine whether paddock surface conditions (e.g. surface hardness or changes in hardness with variable seasonal conditions) influence the frequency of these fractures.

In the current study, Tc fractures were very uncommon compared with T3 fractures, and Tc wedging and dorsal modelling were uncommon. Tc wedging has been reported to be less common than T3 wedging. ${ }^{6}$ Neither horse with a Tc fracture in the current study raced. 
Although it has been suggested that Tc fractures may be associated with a reduced prognosis compared with T3 fractures, at least if managed conservatively, ${ }^{19}$ only small numbers have been reported and a study of sufficient power with a larger number of affected yearlings is needed before making a conclusion.

\section{Conclusion}

Incomplete, and occasionally complete, slab fractures of the T3 occur in juvenile Thoroughbred horses during pasture turnout yet are uncommon. Tc fractures are comparatively rare. Fractures are typically initially detected on survey radiographs of weanlings that are not presented because of lameness. Fracture healing progresses with continued paddock turnout and is complete in around one-third of tarsi within 6 months and in a little over two-thirds of horses if more than 6 months pasture turnout is allowed after diagnosis. Horses with healed T3 fracture performed as well as their peers during their 2and 3-year-old racing seasons. However, it may be incorrect to assume that T3 fracture never affects a horse's ability to race and a larger study is needed before making a firm conclusion regarding the prognosis for racing, the clinical significance of radiographic changes suggesting OA of the DITJ and long-term soundness, particularly for complete fractures that were poorly represented. The effect of Tc fracture on racing career remains to be determined. Further investigation is also needed to determine the factors that may contribute to the occurrence of tarsal fracture in juvenile horses.

\section{Acknowledgments}

The authors thank Scone Equine Hospital for permitting access to their imaging database and radiographic records. Carolind Strong was particularly helpful in assisting with extracting relevant information from the database for the study and provision of additional data.

\section{Conflicts of interest statement}

Scone Equine Hospital supplied the radiographs used in this study. This research did not receive any specific grant from funding agencies in the public, commercial or not-forprofit sectors. None of the authors has any financial or personal relationships that could inappropriately influence or bias the content of the paper.

\section{References}

1. Axling JM, Castle K, Velie, BD et al. Use of diagnostic reports to estimate prevalence and distribution of skeletal lesions in young Thoroughbreds. Vet $J$ 2016;214:72-76.

2. Atwood KE, Spike-Pierce DL, Wittum TE et al. Prevalence and evolution of carpal and fetlock abnormalities in Thoroughbred weanling to yearling sales radiographs. Proc AAEP 2016;62:423-424.

3. Spike-Pierce DL, Atwood KE, Wittum TE et al. Evolution of stifle abnormalities in Thoroughbred weanling to yearling sales radiographs. Proc AAEP 2016;62:430-431.

4. Pilsworth R, Head M. Presales radiographic surveys in yearlings. 1: image interpretation and significance of lesions in the fetlock. In Pract 2010;32:174-178.

5. Pilsworth R, Head M. Presales radiographic surveys in yearlings. 2: Significance of lesions in the carpus, tarsus and stifle. In Pract 2010;32:180-183.

6. Kane AJ, Park RD, Mcllwraith CW et al. Radiographic changes in Thoroughbred yearlings. Part 1: prevalence at the time of yearling sales. Equine Vet $J$ 2003;35:354365.

7. Mcllwraith CW, Kane AJ, Park RD. Changes on radiographs at Thoroughbred yearling sales: prevalence and significance. Clin Tech Equine Pract 2003;2;329-338.

8. Spike-Pierce DL, Bramlage LR. Correlation of racing performance with radiographic changes in the proximal sesamoid bones of 487 Thoroughbred yearlings. Equine Vet J 2003;35:350-353. 
9. Oliver LJ, Baird DK, Baird AN et al. Prevalence and distribution of radiographically evident lesions on repository films in the hock and stifle joints of yearling Thoroughbred horses in New Zealand. NZ Vet J 2008;56:202-209.

10. Jackson MA, Vizard AL, Anderson GA et al. An assessment of intra- and interobserver agreement of reporting orthopaedic findings on presale radiographs of Thoroughbred yearlings. Equine Vet $J$ 2009;46:567-574.

11. Furniss $C$, Carstens $A$, van den Berg SS. Radiographic changes in Thoroughbred yearlings in South Africa. J S Afr Vet Assoc 2011;82:194-204.

12. Miyakoshi $D$, Senba $H$, Shikichi $M$ et al. A retrospective study of radiographic abnormalities in the repositories for Thoroughbreds at yearling sales in Japan. $J$ Vet Med Sci 2017;79:1807-1814.

13. Russell J, Matika O, Russell T et al. Heritability and prevalence of selected osteochondrosis lesions in yearling Thoroughbred horses. Equine Vet $J$ 2017;49:282-287.

14. Kane AJ, Mcllwraith CW, Park RD et al. Radiographic changes in Thoroughbred yearlings. Part 2: associations with racing performance. Equine Vet $J$ 2003;35:366 374.

15. Cohen ND, Carter GK, Watkins JP et al. Association of racing performance with specific abnormal radiographic findings in Thoroughbred yearlings sold in Texas. $J$ Equine Vet Sci 2006;26:462-474.

16. Robert C, Valette J-P, Jacquet $S$ et al. Influence of juvenile osteochondral conditions on racing performance in Thoroughbreds born in Normandy. Vet $J$ 2013;197:83-89.

17. Lindsay WA, McMartin RB, McClure JR. Management of slab fractures of the third tarsal bone in 5 horses. Equine Vet J 1982;14:55-58.

18. Tulamo RM, Bramlage LR, Gabel AA. Fractures of the central and third tarsal bones in horses. J Am Vet Med Assoc 1983;182:1234-1238.

19. Murphey ED, Schneider RK, Adams SB et al. Long-term outcome of horses with a slab fracture of the central or third tarsal bone treated conservatively: 25 cases (1976-1993). J Am Vet Med Assoc 2000;216:1949-1956.

20. Elce YA, Ross MW, Woodford AM et al. A review of central and third tarsal bone slab fractures in 57 horses. Proc AAEP 2001;47:488-491.

21. Bathe AP, Riggs $C$, Boyde A. Investigations into the aetiology of tarsal slab fractures in Thoroughbred racehorses. In: Proceedings of the Veterinary Orthopedic Society 38th Annual Conference, Snowmass, CO, 5-12 March 2011:A12-A21.

22. Barker WH, Wright IM. Slab fractures of the third tarsal bone: minimally invasive repair using a single $3.5 \mathrm{~mm}$ cortex screw placed in lag fashion in 17 Thoroughbred racehorses. Equine Vet J 2017;49, 216-220.

23. Baird D, Pilsworth R. Wedge-shaped conformation of the dorsolateral aspect of the third tarsal bone in the Thoroughbred racehorse is associated with development of slab fractures in this site. Equine Vet $J$ 2001;33, 617-620.

24. Byam-Cook KL, Singer ER. Is there a relationship between clinical presentation, diagnostic and radiographic findings and outcome in horses with osteoarthritis of the small tarsal joints? Equine Vet J 2009;41:118-123.

25. Bloodstock.com.au. Auction results. https://salesresults.bloodstock.com.au Accessed January 2019.

26. Racing Australia. Horse racing results. www.racingaustralia.horse. Accessed August 2017. 
27. Daniel AJ, Judy CE, Rick MC et al. Comparison of radiography, nuclear scintigraphy, and magnetic resonance imaging for detection of specific conditions of the distal tarsal bones of horses: 20 cases (2006-2010). J Am Vet Med Assoc 2012;240:1109_ 1114.

28. Lepeule J, Robert $\mathrm{C}$, Bareille $\mathrm{N}$ et al. A reliable severity scoring system for radiographic findings in the limbs of young horses. Vet $J$ 2013;197:52-57.

29. Raes EV, Bergman EHJ, van der Veen $\mathrm{H}$ et al. Comparison of cross-sectional anatomy and computed tomography of the tarsus in horses. Am J Vet Res 2014;72:1209-1221.

30. Baxter G, Dechant J. Diagnosis of distal tarsal osteoarthritis in horses. Comp Cont Educ Pract 2003;25:138-147.

31. Sprackman L, Dakin SG, May SA et al. Relationship between the shape of the central and third tarsal bones and the presence of tarsal osteoarthritis. Vet $J$ 2015;204:94-98.

32. Whitton RC, Murray RC, Buckley C et al. An MRI study of the effect of treadmill training on bone morphology of the central and third tarsal bones of young Thoroughbred horses. Equine Vet J Suppl 1999;30:258-261.

33. Barneveld A, van Weeren PR. Early changes in the distal intertarsal joint of Dutch Warmblood foals and the influence of exercise on bone density in the third tarsal bone. Equine Vet J 1999;S31:67-73.

34. Gallio M, Azevedo M, Brass KE et al. Bone changes prevalence in the tarsus of Crioulo yearlings up to 26 months of age. Ciênc Rural 2014;44:1442-1447.

35. Mcllwraith CW, Anderson TM, Sanschi EM. Conformation and musculoskeletal problems in the racehorse. Clin Tech Equine Pract 2003;2:339-347.

(Accepted for publication 22 January 2019)

\section{Figure 1.}

Figure 2. Radiographic views (D55-65MILO) of the tarsi of weanling or yearling Thoroughbred horses with third tarsal bone (T3) fractures. Based on the radiographic appearance the stage of fracture healing was described as (a) stage 1 if there was a radiolucent line with sharp clear edges, (b) stage 2 if there was slight blurring of the fracture line, (c) stage 3 if there was marked blurring of the fracture line, (d) stage 4 if the fracture line was partly $(<50 \%$ of its length) ossified and (e) stage 5 if the fracture line was ossified in most areas ( $>50 \%$ of its length) but still had a short remaining fracture line evident. If healing was complete, the previously diagnosed fracture was described as stage 6 (not

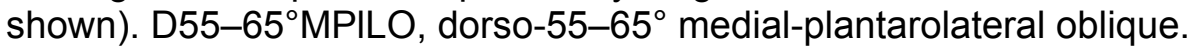

Figure 3. Radiographic views of the tarsi of a Thoroughbred filly. Survey radiographs $(\mathrm{a}-\mathrm{c})$ were taken at 10 months of age and repository radiographs (d-f) 6.5 months later. (a) D55-65 MPILO view of right tarsus with stage 3 fracture (arrow), moderate periarticular modelling, possible fracture of Tc and fragmentation of the distal dorsal lateral aspect of the margin of the PITJ. (b) D55-65'MPILO view of left tarsus with a stage 3 Tc fracture (arrow) and moderate dorsal modelling, and (c) lateromedial (LM) view of the left tarsus with moderate Tc wedging, an incomplete fracture of the dorsal proximal aspect of the third metatarsal bone (arrow) and periarticular modelling and osteophytosis of the DITJ. When repository radiographs were obtained at 16.5 months of age, (d) the D55-65 MPILO view of the right tarsus revealed that healing of the T3 fracture had progressed to stage 5 and was 
only evident as a short, faint lucency extending 2-3 $\mathrm{mm}$ vertically from the distal articular surface (arrow) and the dorsal modelling of Tc was less irregular, (e) the D55-65 MPILO view of the left tarsus revealed that the Tc fracture was barely evident (stage 5), yet the fracture within the proximal third metatarsal bone of the left tarsus was still clearly evident on the LM view (f). DITJ, distal intertarsal joint (centrodistal joint); PITJ, proximal intertarsal joint (talocalcaneal-centroquatral joint); T3, third tarsal bone; Tc, central tarsal bone. 
Table 1. Percentage of examinations of radiographs of Thoroughbred horses with tarsal slab fractures staged between 1 and 5 compared with total examinations per year.

\begin{tabular}{cccc}
\hline Year & $\begin{array}{c}\text { No. of } \\
\text { examinations with } \\
\text { T3 fractures (\%) }\end{array}$ & $\begin{array}{c}\text { No. of } \\
\text { examinations } \\
\text { with Tc } \\
\text { fractures (\%) }\end{array}$ & $\begin{array}{c}\text { Total no. of } \\
\text { examinations }\end{array}$ \\
\hline $\mathbf{2 0 1 0 ^ { \text { a } }}$ & $10 / 838(1.19 \%)$ & $0(0)$ & 838 \\
$\mathbf{2 0 1 1}$ & $26 / 1232(2.11 \%)$ & $1(0.08 \%)$ & 1232 \\
$\mathbf{2 0 1 2}$ & $24 / 1106(2.17 \%)$ & $2(0.18 \%)$ & 1106 \\
$\mathbf{2 0 1 3}$ & $23 / 980(2.35 \%)$ & $0(0)$ & 980 \\
$\mathbf{2 0 1 4}$ & $39 / 1322(2.95 \%)$ & $0(0)$ & 1322 \\
$\mathbf{2 0 1 5}$ & $42 / 1752(2.40 \%)$ & $0(0)$ & 1752 \\
$\mathbf{2 0 1 6}$ & $20 / 446(4.48 \%)$ & $0(0)$ & 446 \\
& & $3(0.04 \%)$ & 7676 \\
\hline
\end{tabular}

${ }^{\text {a S}}$ Study included radiographs from 1 June 2010 to 1 April 2016.

T3, third tarsal bone; Tc, central tarsal bone. 


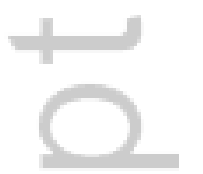

4 


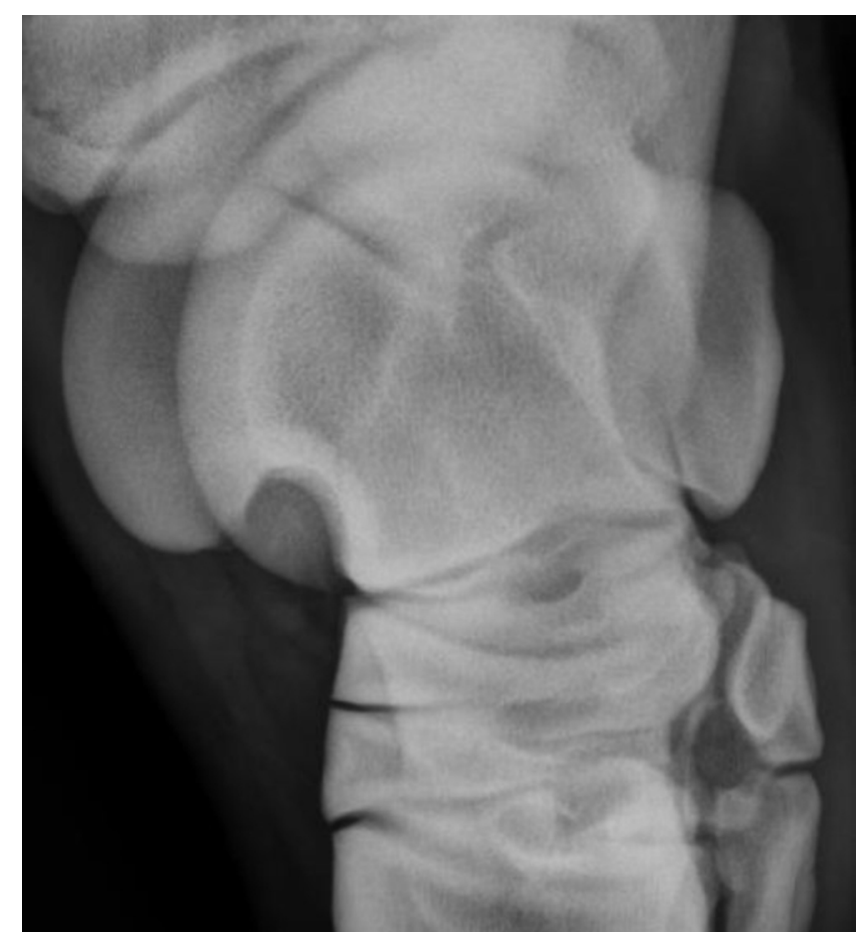

avj_12790_f1a.jpg

This article is protected by copyright. All rights reserved. 


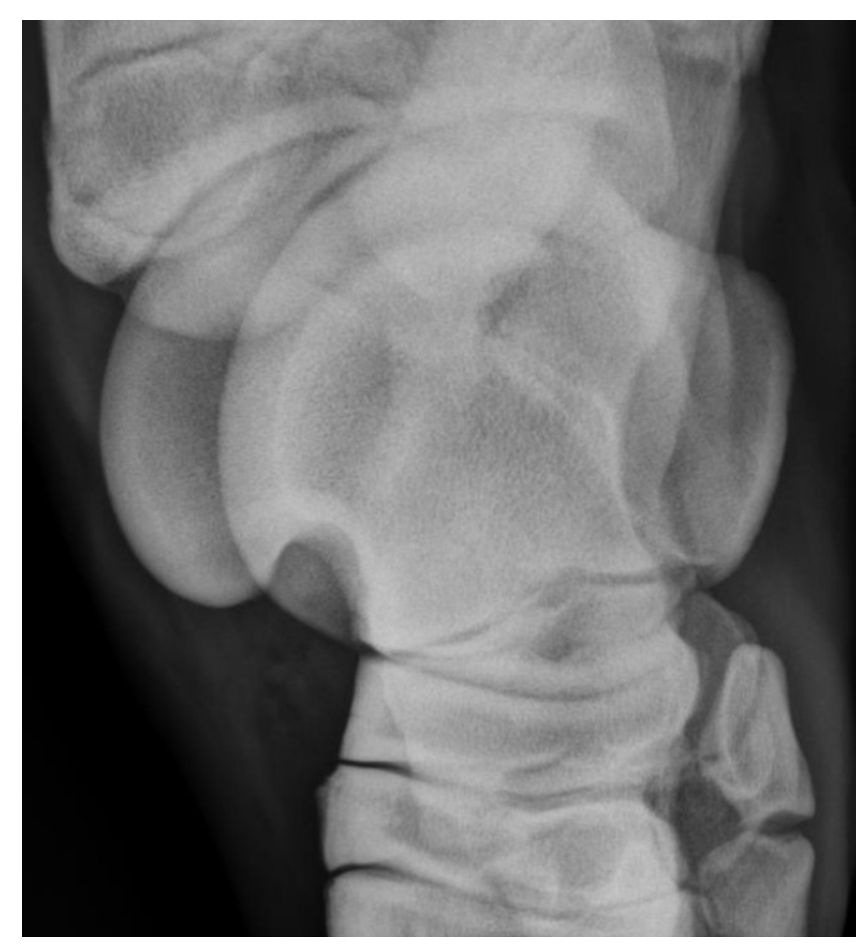

avj_12790_f1b.jpg

This article is protected by copyright. All rights reserved. 


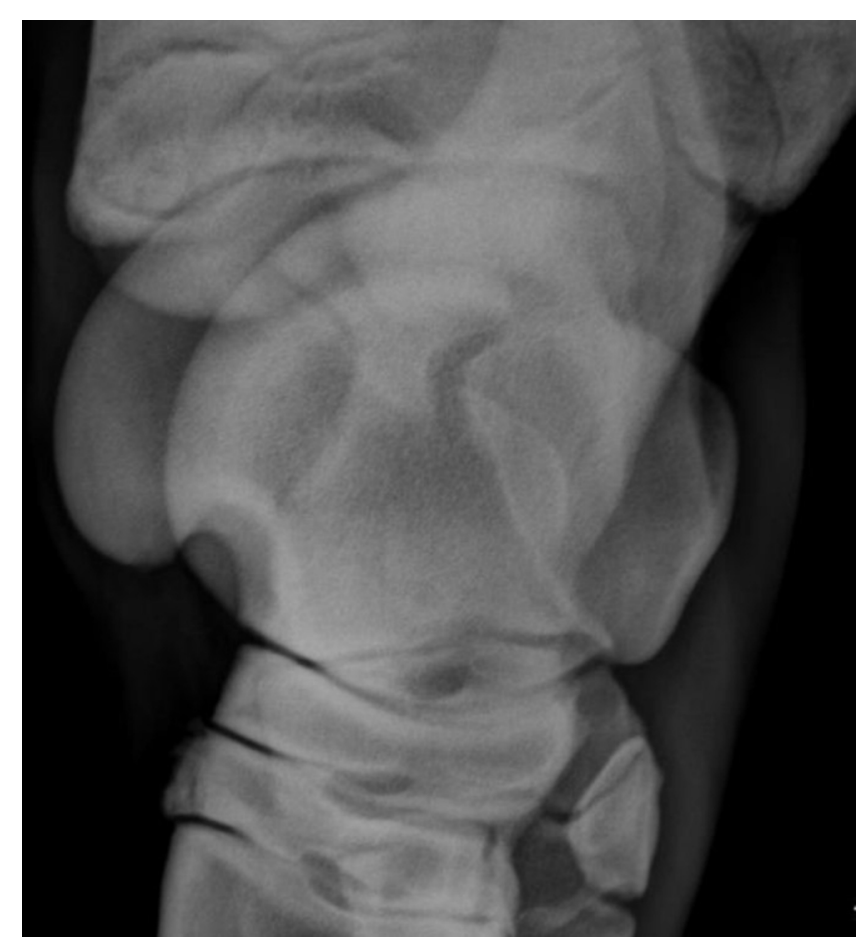

avj_12790_f1c.jpg

This article is protected by copyright. All rights reserved. 


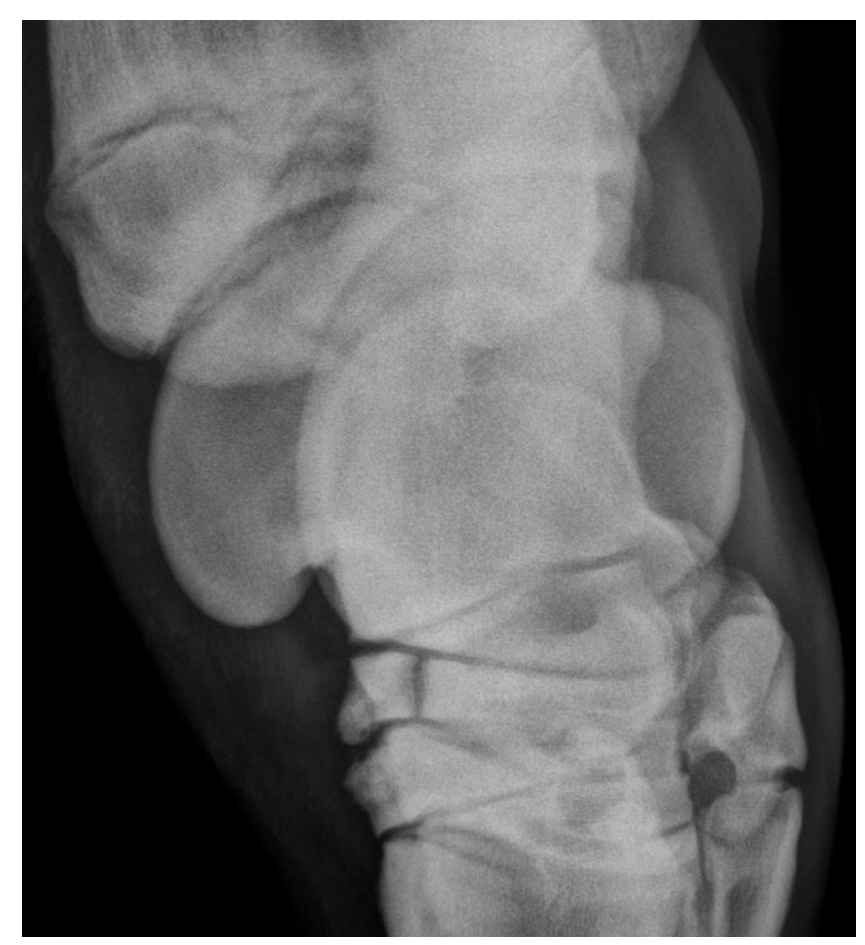

avj_12790_f1d.jpg

This article is protected by copyright. All rights reserved. 


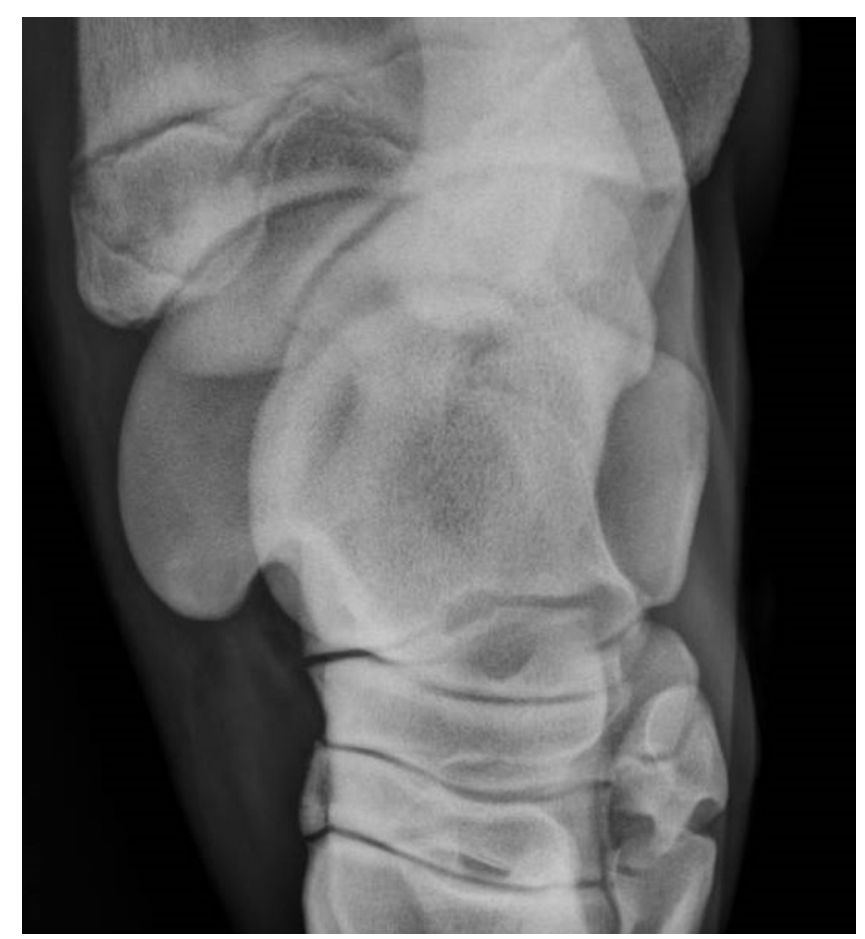

avj_12790_f2a.jpg

This article is protected by copyright. All rights reserved. 


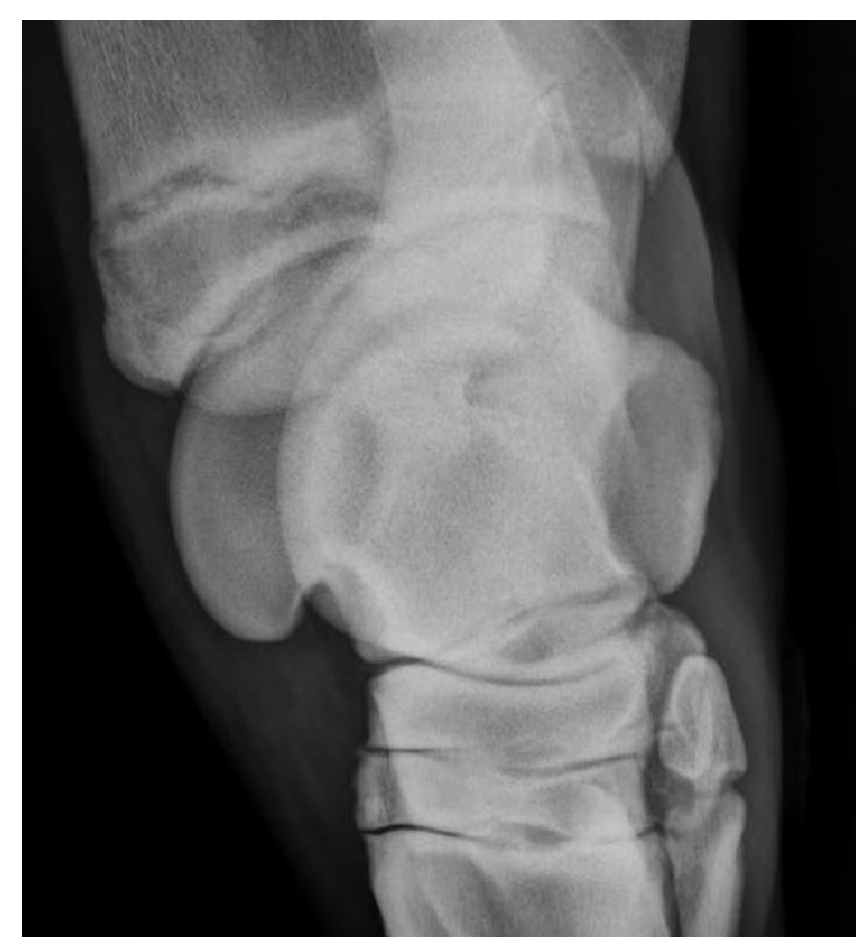

avj_12790_f2b.jpg

This article is protected by copyright. All rights reserved. 


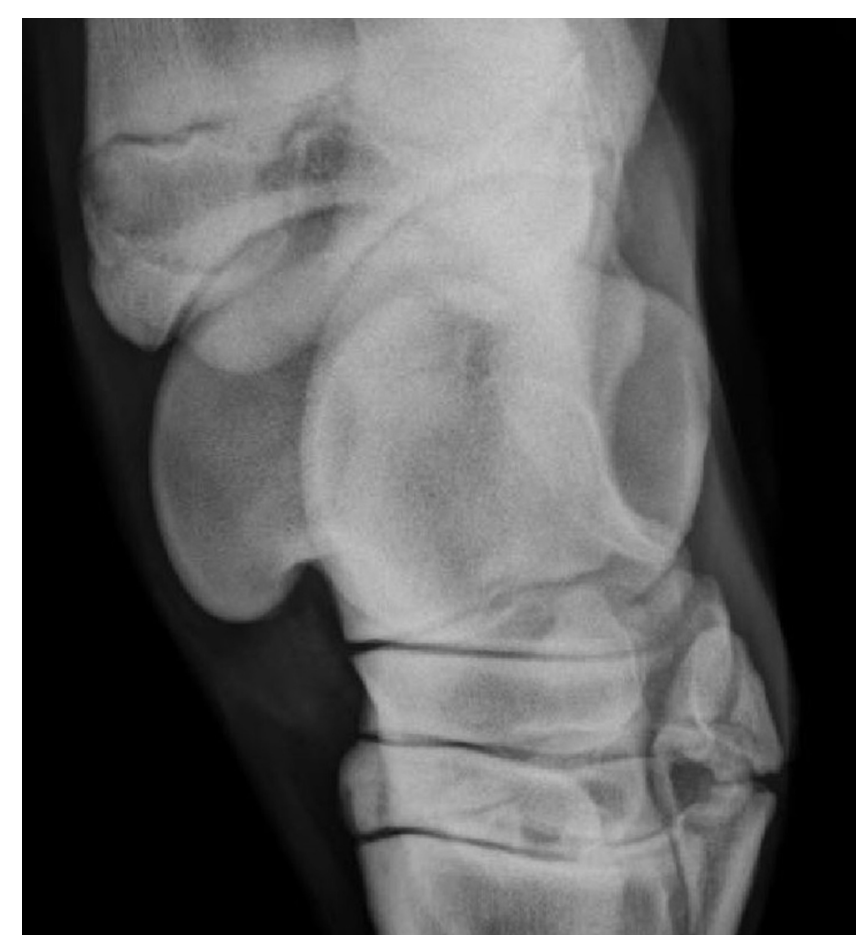

avj_12790_f2c.jpg

This article is protected by copyright. All rights reserved. 


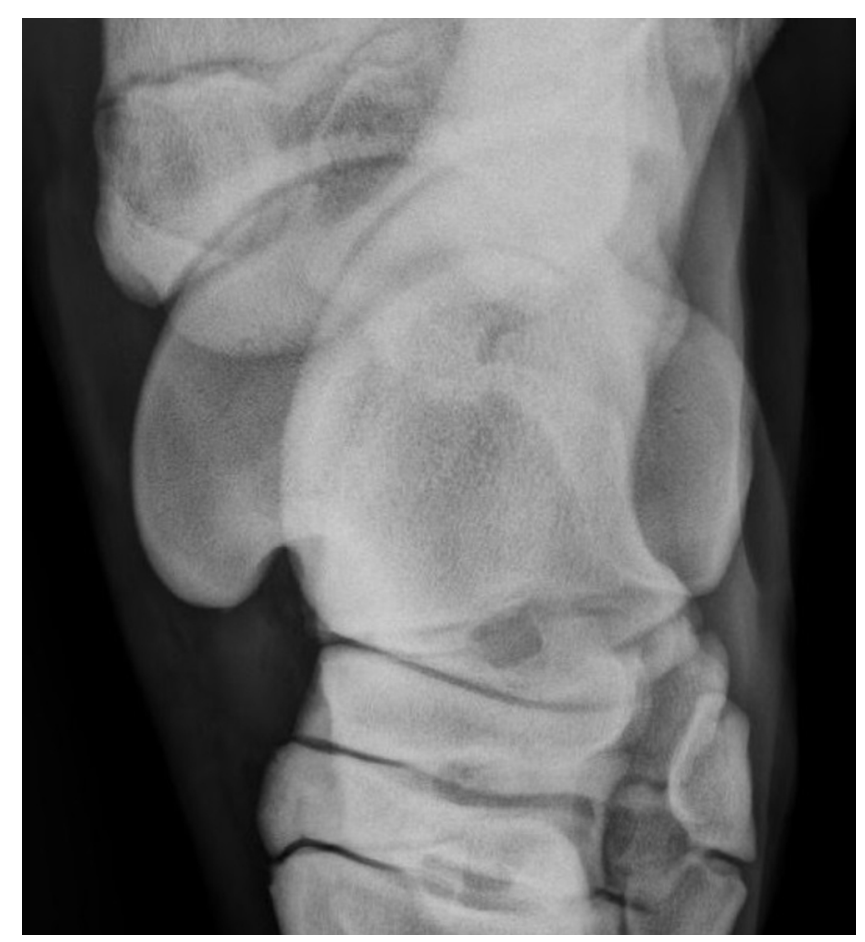

avj_12790_f2d.jpg

This article is protected by copyright. All rights reserved. 


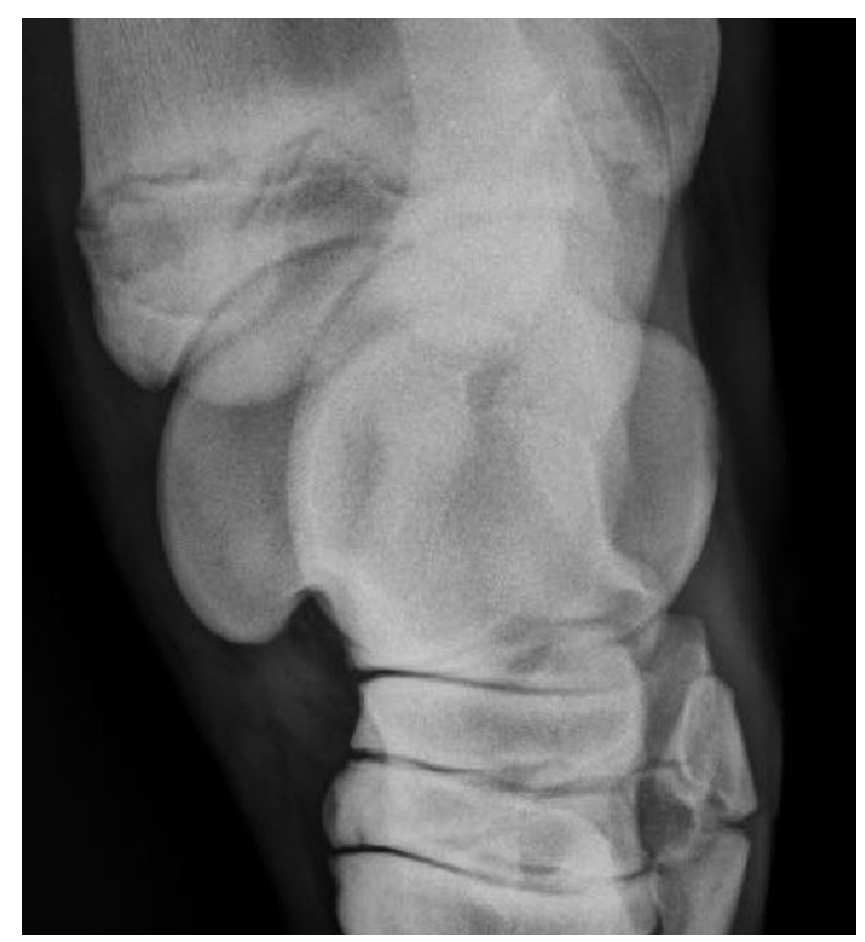

avj_12790_f2e.jpg

This article is protected by copyright. All rights reserved. 


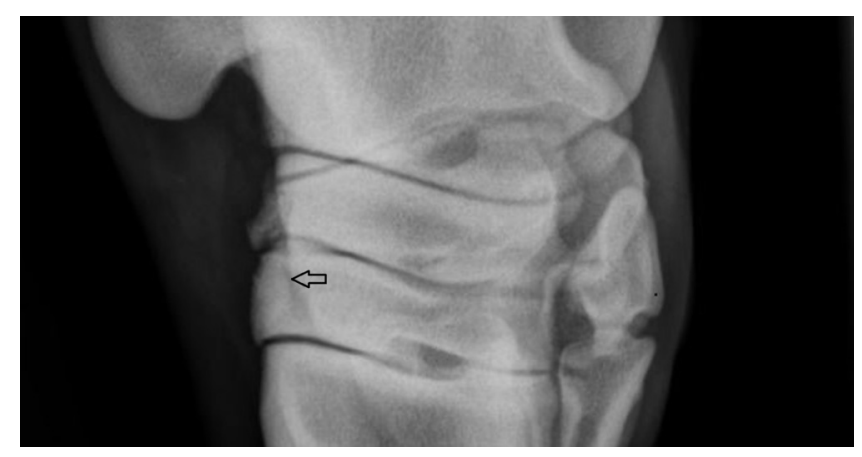

avj_12790_f3a.jpg

This article is protected by copyright. All rights reserved. 


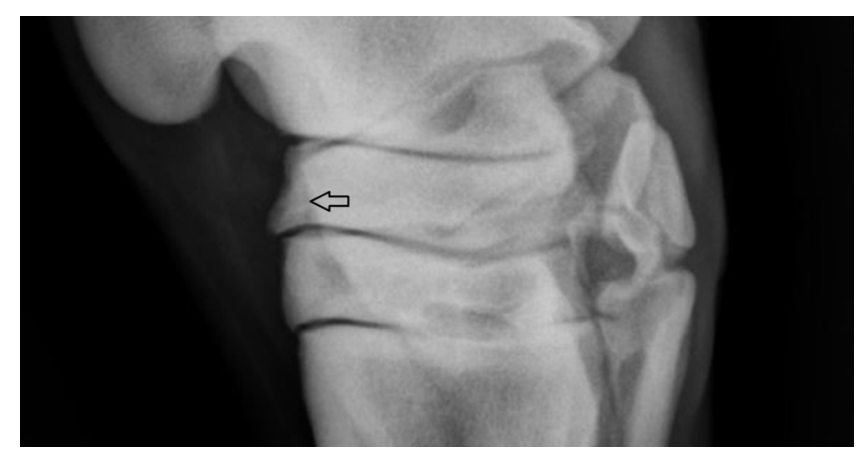

avj_12790_f3b.jpg

This article is protected by copyright. All rights reserved. 


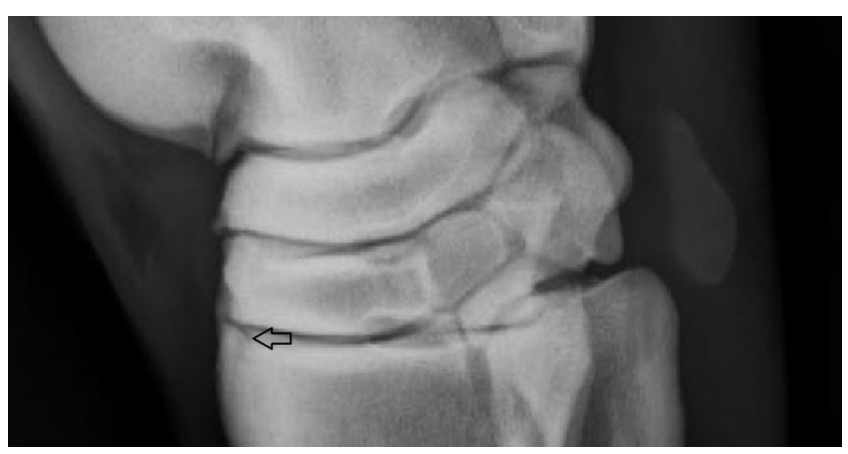

avj_12790_f3c.jpg

This article is protected by copyright. All rights reserved. 


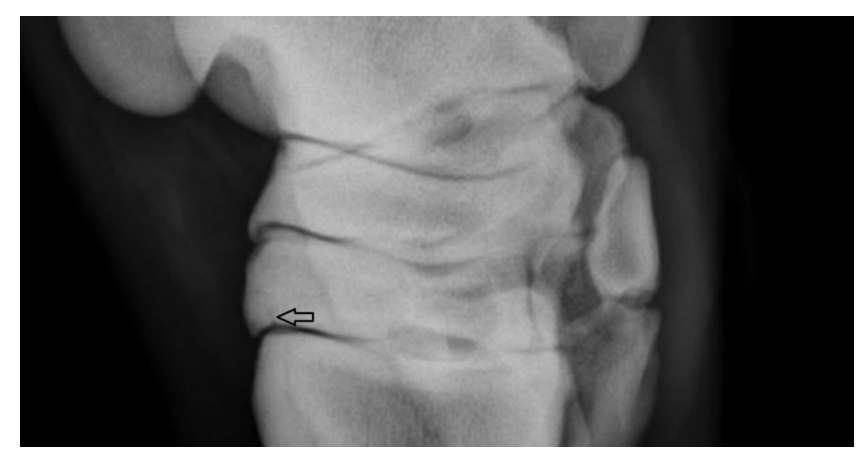

avj_12790_f3d.jpg

This article is protected by copyright. All rights reserved. 


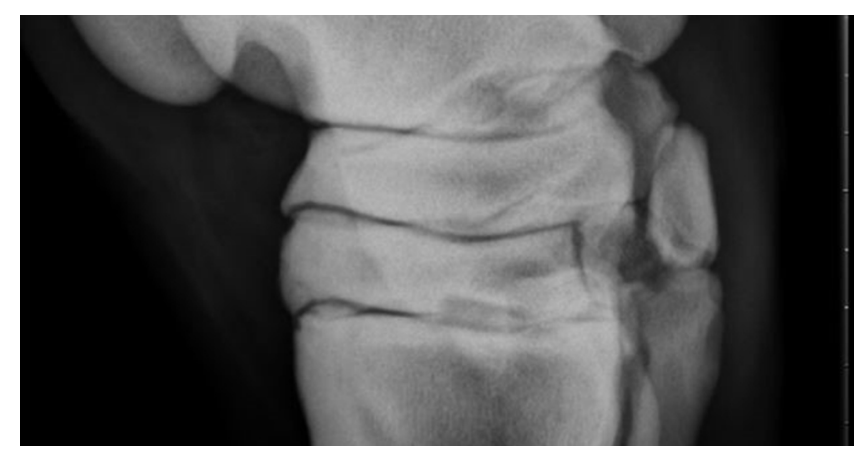

avj_12790_f3e.jpg

This article is protected by copyright. All rights reserved. 


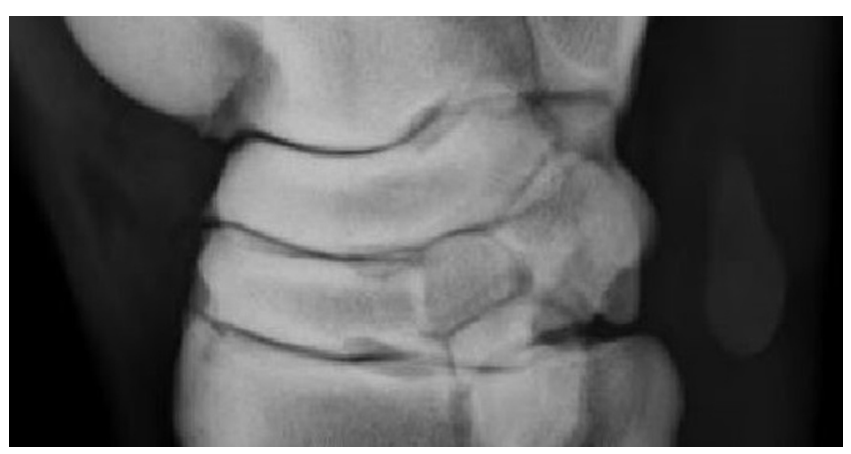

avj_12790_f3f.jpg

This article is protected by copyright. All rights reserved. 


\section{University Library}

\section{- M M N E R VA A gateway to Melbourne's research publications}

Minerva Access is the Institutional Repository of The University of Melbourne

Author/s:

Steel, CM;Collins, VL;Hance, SR;Adkins, AR;Hitchens, PL

Title:

Prevalence, radiographic resolution and outcomes of slab fractures of the third and central tarsal bones in juvenile Thoroughbred horses

Date:

2019-04-01

Citation:

Steel, C. M., Collins, V. L., Hance, S. R., Adkins, A. R. \& Hitchens, P. L. (2019). Prevalence, radiographic resolution and outcomes of slab fractures of the third and central tarsal bones in juvenile Thoroughbred horses. Australian Veterinary Journal, 97 (4), pp.108-115. https:// doi.org/10.1111/avj.12790.

Persistent Link:

http://hdl.handle.net/11343/285648 